\title{
'No Borders' and Complexity
}

\section{Bert Olivier}

\section{Abstract}

This paper scrutinises the idea of 'no borders' - ultimately in relation to the question of curricula design - in the light of complexity theory, that is, the theoretical complex predicated on the unmitigated complexity of the interconnected systems that comprise the planetary ecosystem of the earth. Such 'systems' include all social and biological systems and subsystems - in a word, all living as well as inorganic things, to the extent that the latter affect the lives of the former. In this sense a forest is a complex ecosystem, as is a community of people, or even a family. These are instances of complex (eco-) systems because of their being 'open' to the environments in which they exist; that is, they change as totalities of interconnected individual components, at the same time as the individual components change in relation to changes that occur in their environments. This is easily demonstrated, first, by means of a discussion of modernism, postmodernism and poststructuralism - the latter of which recognises complexity - and secondly with reference to socio-economic subsystems, such as families, living in certain economic environments (which comprise, in their turn, larger subsystems of which the families form a part) if economic conditions in the latter deteriorate, they affect the former detrimentally, and vice versa. The same is true of natural eco-subsystems, and here the example of an entomological eco(sub)system explored in literary fiction - that is, fiction rooted in biotic reality - is employed to drive the point home of the intimate interconnectedness of all complex eco-subsystems in the world. The point of this demonstration of the character and implications of complex interconnectedness is to provide a powerful incentive for the transmutation of curricula in South Africa (and by implication the world) in the direction of design that recognises and presupposes such complexity, so that no item in a curriculum will blindly suggest its isolation from everything around it, but, on the contrary, acknowledge its unavoidable interconnectedness. 
Keywords: borders, complexity, ecology, interconnectedness, poststructuralism

Change is ubiquitous, and stability and certainty are rare. Complexity theory is a theory of change, evolution, adaptation and development for survival. It breaks with simple successionist cause-and-effect models, linear predictability, and a reductionist approach to understanding phenomena, replacing them with organic, non-linear and holistic approaches respectively $\ldots$ in which relations within inter-connected networks are the order of the day ... (Keith Morrison 2008: 16).

\section{Introduction: What is a Complex System?}

It is probably true that most people do not know what complex systems are, and that these systems presuppose constant change across the board, despite the fact that everyone one is enmeshed in several such complex systems every minute of the day and night. In fact, the human body is a complex system, given that there is constant interaction between all its physical and neural constituent parts, and that it also interacts with its environment in complex, often unpredictable ways. The very consideration that the human brain comprises billions (about 100 billion) of neurons (nerve cells), among which old and new neural pathways are constantly activated, already demonstrates the complexity of the body in question. When one approaches this 'body' as an 'embodied human being' the complexity only increases, because then the brain becomes the basis for what is called 'mind' (or 'spirit', in an older idiom) as its 'function', and its 'environment' becomes multi-dimensional - not just physical, but social, psychological, cultural, and so on, in all of which contexts the embodied person is inserted in complex, open-ended ways. As will be argued below, this link between complexity and open-endedness is of decisive importance for understanding the world in which we live. This is one of the chief reasons why curricula in contemporary schools and universities should be designed with complexity in mind - not only the complexity of every student as a human subject (see the section on Lacan, below) and of each discipline that they are taught, but the complexity of the multiple interactions 
between students (and between teachers or lecturers) and disciplines, students and teachers or lecturers, and between the (open-ended) disciplines and the constantly changing world which they reflect scientifically and intellectually. In what follows I shall examine the question of complexity in various contexts, to be able to demonstrate that it is imperative for school as well as university education to incorporate the study of complex, interconnected systems into curricula in the natural as well as the social sciences and the humanities. My reason for saying that this is imperative should be obvious: if education of the young is broadly the systematic preparation of young people for their entry into the world of adult responsibilities at several levels - social, moral, political and professional, to mention only some - then educators would renege on their duty, unless the world they introduce these young people to were presented in all its complexity as the world of the $21^{\text {st }}$ century. By 'complexity' I don't only mean something numerical, such as a world with a total population of more than 7 billion people, although this adds to its complexity. What I have in mind is that the total (and constantly changing) number of living beings in the world (humans included) are all interconnected in systemic ways, including economically and biologically, and these are interconnected, in turn, with inorganic natural elements such as air, soil and water. The consequences of complex interconnections amount to continuing changes taking place all the time, as different elements and actors continually affect one another. For example, human economic activities affect the quality and composition of the air, soil and water on the planet, which affect all living beings in turn, in an ongoing reciprocal process. In total, as will become apparent in the rest of this paper, all these mutually connected subsets of elements comprise the planetary ecosystem, which is an almost incomprehensibly complex system. Importantly, global educational systems in all countries, and in every distinguishable country, comprise a complex system with many variables. The argument of this paper is that these educational systems should reflect the complexity of the world - of a 'borderless world' - in which they are situated and of which they form a part, lest the beneficiaries of the system - the students - be left uninformed and unprepared for the complex events and processes that they are likely to experience as adults.

Another such complex system is language, which we use more or less all the time, except when we sleep, and even then, should we dream, we are enmeshed in another such system, that of the unconscious (which, according to Lacan's [1977: 234] famous dictum, 'is structured ... like a language'). It 
should be easy to grasp the complexity of language if we consider its so-called 'diacritical' structure, that is, the fact that, as Ferdinand de Saussure (1959: 6570) noted, language, considered as a system of 'signs' - with each sign consisting of a 'signifier', like a printed or spoken word, or an image, and a 'signified', or concept - has no 'positive' terms, but only 'differences'. This may seem counter-intuitive, but just consider that the meaning (or signification) of a word (or signifier) such as 'cat' does not depend - as it may seem to - on its 'reference' to a furry creature that utters the sound 'miaow'; this 'connection' is entirely arbitrary and conventional. The word 'cat' might just as well have denoted an animal that barks, which just happens to be called 'dog' in English, again arbitrarily, and vice versa. The 'meaning' of 'cat' is a function of differences - between 'cat', 'sat', 'that' and 'mat', for example, but also between 'cat', 'tiger', 'leopard', 'dog', 'lion', 'jaguar', 'panther', and so on - insofar as every word might be said to carry the (invisible, but implied) 'trace' of every word that it is not. This insight on Saussure's part was a stroke of genius, because it explains many things about language, for instance why the word 'Brontosaurus' has meaning even though none of the creatures that it names exist any longer, or have ever been seen by any human, and also why words called 'abstract nouns', like 'love', or 'anxiety', have meaning despite lacking corresponding 'things' they supposedly 'refer' to. They have meaning because of the differential relationships between each word and all others in the system of language, particularly words that are related to such words, including (in these cases) 'feelings', 'affects' and 'emotions', which interact reciprocally with them to generate meaning.

To make this clearer, and simultaneously clarify the claim, that language is a complex system, consider that one of poststructuralist Jacques Lacan's metaphors for the way language works, that is, for the 'signifying process', is his image of language as a train (Lacan 1977a: 152) moving across the landscape with people in it - which is a way to show that, as speaking beings, we 'inhabit' language, or are 'in language'. The advantage of this metaphor is that it allows one to grasp the positioning of the subject within language, here envisaged as a boy and a girl sitting opposite each other in a train compartment, and therefore 'seeing' things from their respective 'angles' through the train's (that is, language's) 'windows'. As the train pulls into a station, the boy sees a sign on a public toilet, 'Men', erroneously as naming the town station where they have arrived, while the girl, making the opposite mistake because of her position on the opposite seat, sees it as 'Ladies' and 
'corrects' him accordingly. The moral of the story is that individuals all understand things from the perspective of their position on or in the 'train' of language, and moreover, that our gender makes a difference in the way we understand things linguistically. In addition, the fact that language is conceived of as a 'train' - something that travels or moves through time and space accommodates the fact that language, like everything else in the world, is subject to historical change. This image of a train occupied by passengers, used by Lacan to represent language, gives a good impression of the complexity of language as an open system: it consists of different, but connected, coaches and compartments (the words or signs), to which new ones can be added; it is open to new 'occupants' (the speakers of a language); it moves from place to place in time (language is open, or subject to historical change); and, depending on the human subject's gender, the world is perceived and understood differently (which probably gives rise to more problems and misunderstandings in inter-gender communication than between individuals of the same gender). Therefore, if we imagine language as an impossibly colossal train, with all the world's inhabitants on it, incessantly travelling through time and space (history), the number of 'perceptions', and corresponding linguistic utterances to articulate these perceptions, on the part of innumerable people of different cultures and genders, would be utterly unrepresentable, because of their complexity and open-endedness in numerical as well as semantic (meaning-related) terms.

A complex system (mentioned earlier) in which all living beings are inescapably enmeshed is nature (Kovel 2007: 95-120), or more broadly, the planetary ecosystem, which itself consists of numerous ecological subsystems. Most people have probably heard about the so-called 'butterfly effect', that goes more or less like this: 'If a butterfly flaps its wings in China, it causes a hurricane in Brazil'. This saying is paradigmatic of the dynamics of complex systems; what it captures, is the ecosystemic interconnectedness of everything on planet Earth (an 'ecology' is an interconnected totality of components), as well as the fact that one tiny event may lead causally to a much larger event or events. If this sounds far-fetched, consider that signs of radioactive contamination of the sea after the Fukushima nuclear industrial accident in Japan a few years ago were detected on the American coast sometime later. It is not only human trade and culture that are globalised; everything that happens on the planet, from such accidents to natural occurrences, have effects that reverberate around the globe. This represents what one understands by 
'complexity'. The reason for such occurrences is - as already intimated above - that complex systems comprise interconnected totalities of elements and are characteristically 'open', instead of closed. As I learned years ago from my friend and complexity theorist, Paul Cilliers of Stellenbosch University - one of the most talented of South Africa's philosophers until his untimely death not so long ago - one should distinguish between 'complex' and 'complicated' systems (Cilliers 1998: 3). A complicated system is something like the internal combustion engine of a motor car - it consists of many moving parts that work together 'systematically', so that if one breaks down, the operation of the machine as a whole would be negatively affected. But it does not change in relation to its environment by 'adapting' to it when the latter changes; that's what makes it a 'closed' system. In fact, it would have been extremely beneficial to the planet if such machines did represent 'open' systems that respond to changes in their environment, and accordingly, adapted spontaneously to global warming by switching to the use of water as fuel, instead of petroleum! Cilliers (1998: 2-5) also provides a handy list of features encountered in complex systems, such as that they are open to their environment, comprise a large number of interacting elements, which change in the course of this non-linear interaction (so, the sand on a beach does not qualify as a complex system), that they have a history, and they function under conditions that are not in equilibrium - the latter, he points out, is synonymous with death (1998: 4).

What is important for the theme of this paper is that what makes complex systems so special, is not only that they usually comprise a large number of elements or components, but that that they are 'open' in a double sense: first, they are open to the 'influence' of their environment, and secondly, every one of their component parts is open to changes in the system (even if it 'is ignorant of the behaviour of the system as a whole'; Cilliers 1998: 4) - that is, it is affected by such changes. This is truly a case of 'no borders'. So, for example, a social ecological subsystem such as a family (consisting of several individuals) is embedded in broader subsystems such as schools, urban, suburban or rural areas, which are (in their turn) situated in certain socioeconomic contexts and specific kinds of culture. An individual in a family will unavoidably be affected by all the differences and changes in the broader subsystems in which they live - this is easily understood. Urie Bronfenbrenner's well-known ecological theory for human development (so-called 'develecology'; Shelton 2019), which focuses on the kind of relations involved 
in social systems and subsystems like the ones referred to here (which, in their totality, he labelled 'microsystems', 'mesosystems', 'exosystems', 'macrosystems', 'chronosystems', and 'ecosystem', respectively; Shelton 2019: 11), encompasses human or social ecology, situated within an overarching ecological system, and shows how everything in (and 'surrounding') an individual's life co-determines his or her relative well-being in complex ways. The complexity of a person's insertedness in these overlapping subsystems can be gauged from Shelton's succinct account of Bronfenbrenner's schema for understanding it (Shelton 2019: 10):

Bronfenbrenner's scheme is a system of concepts: the person exists in a system of relationships, roles, activities, and settings, all interconnected. Individual development takes place as the developing person ages, constructs an understanding of his or her experience, and learns to act effectively within the system in which she or he is participating. Simultaneously, the development of the person changes the system. The system changes because as a person develops, his or her actions change, and other people in the system therefore respond differently to the developing person. At the same time, the settings the person participates in are interrelated with each other and with other settings. As well, the settings are part of the culture in which the whole system of settings and the roles, relationships, and activities within them are embedded.

It is not difficult to grasp the virtually untraceable, constantly changing and increasing, number of interactions (and their effects) among people and settings that this involves. As in the case of the weather, where the principle of 'sensitivity of initial conditions' functions - which means that if one variable, for example temperature, or wind-direction, in existing weather conditions changes, the entire forecast for an area changes - Bronfenbrenner's account of complex social conditions implies that every individual action in a social context has an effect on the actions of others, which, in turn, change the social context, and the latter, again, influences future actions of people involved. The current (February 2019) actions on the part of Donald Trump (the 'president' of the United States) regarding his obsession, to have a wall built between America and Mexico, are having a series of 'effects' on Democratic lawmakers, insofar as his actions provoke reactions on their part, which, again, 
provoke reactions on his (and other Republicans') part, as well as on members of the public in America and on politicians and the public in the rest of the world, and so on, and so on... Who can trace the complex, ever-growing web of actions and reactions in this process? And this is only one instance of an action on the part of one - albeit prominent - individual in the world!

One could refer to this complex phenomenon as an instance of the 'social sublime' too, which functions as an index of the general 'complex' structure of social relations in a community (and more broadly, society) (Olivier 1998). Unless those responsible for curriculum design were to consider the implications of such complex social interactions - and the implications of these with regard to the encompassing natural world, which is unavoidably affected by what human beings do, and reciprocally affect humans again in its changed condition (and so on, and on) - they would not do justice to the demands of a thorough, socially and naturally oriented education for the youth. So, for example, neither curricula in agriculture nor in sociology should/would be designed in a vacuum, but with full cognisance of the changing terrestrial climate, which is already affecting agricultural as well as social practices. The same goes for the problematical interface between university management and curricula in economics, which still tends to be predicated on an outdated neoliberal model that does not take endemic poverty into account, and which therefore fails to explain the grounds of student protests concerning economic exclusion. Only if it is recognised that there are 'no borders' between the various fields of human (and other living beings') activities, can curricula be designed that would yield insight into desirable ways of negotiating these.

\section{Poststructuralism and Complexity}

One way of understanding complexity is to take note of the differences between modernism, postmodernism and poststructuralism, which are rooted in the ancient quarrel between Parmenides and Heraclitus. Parmenides argued that only being is, and becoming is not. Things of the world of perception, the world of the Many, of time and change, are subject to becoming, and therefore are not in the true sense. Only being, or the One, which cannot be perceived by the senses, but is apprehended exclusively through thinking, truly is. Heraclitus is reported as having argued exactly the opposite, namely that everything is subject to becoming, or change, as expressed in one of his 
sayings, namely, 'panta rei' - 'all is flux'. But they nevertheless are, according to him, because they are held in existence by what he called the logos (Melchert 1991: 17-26) - the way that the two ends of a bow are held together by the bowstring, and without which it could not be used in archery. Corresponding to these two extremes, modernism is a mode of thinking that attempts to locate being or a sense of permanence within the flux of existence by finding the One there, while postmodernism is content to abandon any sense of being in favour of the Many, becoming or flux. Poststructuralism steers a path between the two, 'thinking them together', or negotiating a course between the Scylla of sterile permanence and the Charybdis of incessant change, demonstrating in different ways that being and becoming cannot, or should not, be separated, and that each is limited by the other, in this way allowing change and stability to enter into a life-giving contract. This bringing-together, without synthesis or reconciliation, of being and becoming by poststructuralist thinkers has introduced complexity into the human sciences (because strictly speaking the two concepts are mutually exclusive), and it bears a resemblance to the socalled 'indeterminacy (or uncertainty) principle' in quantum mechanics, which states that one cannot measure, precisely, the velocity and the position of an electron orbiting the nucleus of an atom at the same time, not even in theory the one excludes the other, and yet, both can be 'thought' together (see Encyclopaedia Brittanica 2019).

In the 19th century Charles Baudelaire formulated the difference between the modern and the postmodern (probably unwittingly) when he pointed out that what he called the 'modern artist' has a twofold task: firstly, to be receptive to all the endless change, particularity and transformation (the Many) around him or her, but secondly, to find and articulate that which is essential, permanent, lasting or universal (the One) within the perpetual flux of modern existence (Harvey 1989: 20). Although he did not use the terms, what he described corresponds to what are known, today, as the postmodern and the modern, respectively: poets, filmmakers, novelists, architects or artists who record, stress or capture incessant change or becoming in their work in innovative ways (absent any attempt to stabilise such becoming), are by that token postmodernists, while those who look for elements of being within the flux, or arrest it by different means, are by that token modernists. Needless to stress, there are many ways to effect either of these strategies in the different arts - in literature John Fowles used multiple endings (The French Lieutenant's Woman; 1977) and telescoped narratives within narratives 
(Mantissa 1997) in his novels as postmodernist devices, for example. It is true, however, that a closer inspection of a novel such as his The Magus (1983; see Olivier 2008) reveals a poststructuralist structure that interbraids being and becoming, not allowing either to prevail over the other. On the other hand, Virginia Woolf reveals her modernist temperament by using images of becoming, like the intermittent flash of light from a lighthouse (To the Lighthouse; 1994), or waves (The Waves 1959), in conjunction with preponderant ones of being, such as the never-changing nature of light itself, or of the ocean, which reveals itself in the epiphany of the recurrent lighthousebeam, or the regularity of the waves breaking on the beach.

Søren Kierkegaard, too, generously gave us 'models' for conceptualising modernism, postmodernism and poststructuralism. In Either/ Or (Volume 1, 1971: 281-288; Melchert 1991: 432 - 433; Olivier 2005) he distinguishes (and elaborates on) what he calls the 'aesthetic model' and the 'ethical model' (Kierkegaard 1971a: 141-142, 229, 276; Melchert 1991: 433-436), each of which corresponds to the structure of postmodernism and modernism, respectively. The aesthetic model is postmodernist, structurally speaking, in so far as Kierkegaard describes a mindset and corresponding practices that revel in identity fragmentation (becoming) and aesthetic enjoyment for its own sake (to combat boredom), with no ethical thrust towards a sense of identity (being). The character of A (the aesthete) learns that the method of 'rotating crops' is the best way to overcome the greatest enemy, namely, boredom, not by changing one's surroundings as much as by changing one's mindset. For example, instead of taking anything seriously, aesthetic 'play' is recommended - if you are at the opera, and by chance it is the same opera being staged as the one you saw elsewhere last week, you can change your pattern of enjoyment by coughing in time with the tympanum, or humming along with the strings, and if other members of the audience throw you glances of dismay, so much better; it makes things more interesting.

However, as the character of Judge William tells A in a series of letters (Kierkegaard 1971a), this approach to life means that one is different in every situation, and that your personality has no unifying integrity: you are no one, except a series of masks: the Many. This is the structure of the postmodern. Then Judge William goes on to recommend to A that, instead of this disintegrative lifestyle, he should marry, to combat the worst enemy of all, namely time (Kierkegaard 1971a: 141-142), by renewing your relationship 
with your spouse every day in an inventive way, which would not only prevent you from becoming bored with each other, but would impart a unifying integrity to your personality: the One. In short, you would make your life into a work of art, according to Judge William. This is the model for the modern work of art, as it is structurally characterised by unity, integrity and beauty.

But importantly, as far as complexity goes, Kierkegaard (1971a: 341356; Olivier 2005) also anticipates, in an ingenious manner, the structural outlines of poststructuralism, where he talks of the 'religious model', although he does not follow it through, but eventually makes the switch to faith as a kind of 'leap into darkness'. The suggestive part of the religious model emerges where he writes about how, no matter how much one tries to either practise the aesthetic enjoyment of the aesthetic model (postmodern) by distancing yourself from everything in order to manipulate it fragmentarily for the sake of 'the interesting', or (alternatively) dedicate oneself to the elaboration of a unified self through commitment to one's loved one, integrating all experiences into a single, coherent totality (modern), you always fall between two stools in the ashes. In other words, in either case, as Kierkegaard intimates, you are guaranteed to find that you cannot practise the chosen way of life 'perfectly', without sometimes failing in your intentions. He points out that, as compared to God (who is infinite), we find that we are woefully fallible and finite, and that we cannot perfect whatever we set out to do. This marks the point where Kierkegaard introduces ways to accept one's finitude in relation to an infinite God. However, I (for one) believe that we do not have to leap into faith (as Kierkegaard does), but simply learn the poststructuralist lesson, that we have to interbraid or negotiate what has usually been seen as binary opposites (being and becoming) between which we must choose (the 'aesthetic'/postmodern or the 'ethical'/modern way of living). In this way we do justice to the complexity of life, insofar as we acknowledge that no absolute choices between alternatives construed as 'binary opposites' (such as black and white, man and woman, heterosexual or homosexual, language or images, culture or nature) are possible; we have to 'think them together' insofar as they comprise different, but inescapably related, aspects of the complex fabric of social and natural reality.

Kierkegaard's glimpse of complexity is recognisable here in his recognition that, regardless of which route one prefers to follow - the aesthetic (postmodern) or the ethical (modern) - in practice one ineluctably acts in accordance with both (poststructuralism) at different times, and our action can 
therefore be understood in terms of the complex interweaving of structural elements of both the modern and the postmodern, even if, logically speaking, they are mutually exclusive. Anticipating complexity theory, such a protopoststructuralist move acknowledges that what makes humans the beings they are, is their capacity to practice strategies of 'becoming' (flux, fragmentation, the Many), while simultaneously alternating between these and countervailing strategies of 'being' (stabilisation, coherence, the One) - or better, negotiating these two positions creatively. In other words, don't choose - as Derrida (1978: 369-370) says, we are not in a position to - between the aesthetic (postmodern) and the ethical (modern) as if one is absolutely better than the other - or between the One and the Many, black and white, male and female, sensibility and intelligibility, writing or speech, the engineer or the bricoleur - something our culture has always encouraged us to do, believing that one of these pairs of opposites is somehow 'better' than the other, and establishing axiological hierarchies as a result. Learn to think them together, or approach them in a creative, re-configuring manner. Do not choose between nature and culture, for example, because that way death lies: we need both. This is a poststructuralist way of thinking - not the One or the Many, but the One and the Many. This way we learn to do justice to the richness of life. And this is what students have to discover through curricula structured in a manner that not only teaches them about such complexity, but in addition allows them to experience it in inventive ways, one of which is discussed below in relation to a novel that thematises social and natural complexity.

\section{Lacan and Human Complexity}

Thinking opposites together also enables one to do justice to human complexity, as one learns from psychoanalytical theorist, Jacques Lacan's poststructuralist account of human subjectivity. According to Lacan (Evans 1996: 19-20), human subjectivity is not unitary, but precariously stretched between three registers or orders - those of the 'real', the imaginary and the symbolic. The first (the 'real') marks that order which surpasses language and iconicity (in which the infant subject is immersed 'before' it enters the imaginary and the symbolic). Secondly, the imaginary register is acquired when the subject starts recognising images (for instance the mother's face, and crucially, its own image as her- or himself in the mirror). In the third place, the symbolic register of language as discourse (that is, language in the service of 
power) is acquired by exchanging the 'unary' signifier of the imaginary (an image, that is) for the binary signifier of the symbolic (when one grasps that the world is linguistically structured in terms of binary relations such as empty/full, woman/man, black/white, intelligible/sensible, speech/writing, being/becoming, and so on). The complexity of Lacan's theory emerges from the insight that, while every 'healthy' subject is psychically structured by the interlocking relationships among these three registers (if one lacks one of them, you would be psychotic by definition), they represent very different 'conditions', 'positions' or 'states' of subjectivity, and yet they all co-function through the psychic orientations and actions of the subject.

What I mean is this: the imaginary register is that of the ego or moi (me) - that is, where the subject's sense of a more or less stable 'identity' (being) is located, while the symbolic (social) register instantiates that of the 'I' or je, from the perspective of which the subject speaks, which means that it does not reflect the 'stable' identity of the ego or moi, but instead the constantly shifting position (becoming) of the unconscious, un-objectifiable position which is presupposed by speaking. After all, the moment we try to focus on the 'I' who speaks, we transform it into the objectified 'me'. The 'real', in turn, is that (in each subject) which is not susceptible to either the imaginary (being) or the symbolic (becoming), but surpasses both in an unpredictable fashion it could be the 'savage soul' of childhood (Lyotard), or the 'monster' in you, but it could also be the unexpected 'saint'. The human subject is therefore an amalgam of all three these irreconcilable psychic positions, which means that he or she is simultaneously 'stable' (being) and subject to the flux of language (becoming), as well as to something ineffable (the 'real'). This represents a complex conception of humanity, given the tensions among these three registers of subjectivity.

How would it work in practice to understand individuals in these complex terms - which is the only way to understand them that does justice to being-human, and thus one that should be factored into the humanities' curricula? It is therefore immensely relevant to curriculum design. Needless to emphasise, a study of psychology or of psychoanalysis (the two disciplines are not the same), as well as of literature, philosophy, sociology and anthropology would help students recognise the complex structural dynamics on the part of humans, and it is therefore imperative that curricula be designed with a view to accommodating these; even natural science-courses should be designed with this in mind, insofar as people would benefit from an awareness of being 
inserted in complex natural ecosystems. In practice this would mean that - in addition to what was said earlier about the complex interactions among various subsystems in society, and picking up the initial thread of the complexity of a person - armed with Lacan's three registers (but also with other models of thought that are predicated on complexity, such as Deleuze and Guattari's; see Olivier 2017), the individual subject should be approached as a very complex entity indeed. In the course of the everyday existence of a person, she or he negotiates the differences and tensions among the three registers comprising their unique subjectivity in unpredictable ways, because every day brings new events, even in the course of a familiar routine.

For example, Elize, a second-year humanities student at a university, and doing well in all her subjects, meets an interesting young guy, Anthony a third-year student in the biological sciences - in the student cafeteria. In the course of getting to know him better, she learns from him about the effect of climate change on species extinction, and starts looking at her own subjects with different eyes, for example Mary Shelley's $19^{\text {th }}$-century Gothic novel, Frankenstein, or The Modern Prometheus (1818), which she no longer reads as an example of the genre of Romantic literature only, but as a prognostication, on Mary Shelley's part, of the causal effects of modern science and technology on nature (Olivier 2018). Sharing this with Anthony, the two become conscientised, and join Greenpeace as well as other ecologically oriented organisations, which events, in turn, affect their relationships with their families, either affirmatively or negatively. In Lacanian terms, Elize's ego or self, located in the imaginary register, was transformed by what she learned at the level of the symbolic, first through Anthony's involvement with biology, and then through its effect on her reading of literature. This stirred in her a deep-felt, but in itself inexpressible affinity for nature at the level of the 'real', which, in turn, impelled her, as well as, under her influence, Anthony, to become conscientised and actively involved in promoting ecological interests, which they do at the symbolic (socially oriented) level of ecological discourse. And it does not stop there, because they are enmeshed in social subsystems from the level of the family and the community to that of the university, local as well as national (and perhaps even international) ecological organisations, and so on, at every level of which they influence people regarding action and activism, and are, reciprocally, influenced by the latter. The ever-increasing complexity of such a situation should be obvious. 
Returning to the question of the curriculum in this regard, unless the complexity of individual subjects, as well as the complex interactions among individuals and different social subsystems be kept in mind in their design treating them, including individual students and lecturers, in simplistic terms instead - the curricula involved would reflect a misleading (supposition of) simplicity, or even complicatedness, but would not do justice to the complex connections and transformations that occur daily in society as well as in nature, as the next section will illustrate. Unless the complexity of existing and future relations among all living beings, and between these and inorganic nature be factored into curricula, what students would learn, whether at school or at university, would be a serious distortion of the various aspects of the world that different disciplines pertain to (geography, economics, biology, physics, literature, sociology, psychology, or law, to mention only some).

\section{Humans, Nature and the Dynamics of Complex Systems}

All of the subsystems referred to above, including individual subjects (each of which instantiates a '[sub]system' in the larger subsystem, society) are embedded - as intimated earlier - in the encompassing planetary ecosystem which we usually call 'nature', but can also be called the planetary bio-system if living beings are foregrounded (keeping in mind that these cannot be separated from inorganic nature's meteorological and chemical properties). Not everyone in complexity studies seems to be keenly aware of the importance of recognising the unavoidable interface between human, social subsystems and non-human, natural subsystems as well as the most encompassing ecosystem, or what one can simply call 'nature', however, as is evident from what Peters writes about complexity and knowledge (Peters 2008: xiii):

Complexity as an approach to knowledge and knowledge systems now recognizes both the growth of global systems architectures in (tele)communications and information with the development of open knowledge production systems that increasingly rest not only on the establishment of new and better platforms (sometimes called Web 2.0 ), the semantic web, new search algorithms and processes of digitization but also social processes and policies that foster openness as an overriding value as evidenced in the growth of open source, open 
access and open education and their convergences that characterize global knowledge communities that transcend borders of the nationstate. This seems to intimate new orders of global knowledge systems and cultures that portend a set of political and ethical values such as universal accessibility, rights to knowledge, and international knowledge rights to research results especially in the biosciences and other areas that have great potential to alleviate human suffering, disease and high infant mortality. Openness seems also to suggest political transparency and the norms of open inquiry, indeed, even democracy itself as both the basis of the logic of inquiry and the dissemination of its results.

Peters does allude to 'the biosciences' here, but the overall impression is one of preoccupation with 'knowledge systems' that are supposedly divorced from what they reflect or pertain to, namely social and natural reality. This creates an erroneous impression - the last thing that can be divorced from natural ecosystems is a 'knowledge system', of whatever kind. What better way to explain the functioning of complex systems - their dynamics - than with recourse to a specific work of fiction (a novel) that does acknowledge the complex connections or intertwinements between social and natural ecosystems, which I have chosen to do for the additional reason of demonstrating how literature can be harnessed in the course of teaching a curriculum that is predicated on complexity. With misleading simplicity, the novel is called Flight Behaviour (2012), written by one of the world's outstanding novelists, Barbara Kingsolver, also author of the powerful anti-colonial novel, The Poisonwood Bible (1999; see Olivier 2018a), which I could also have used here to demonstrate the workings of complex systems. Why 'misleading simplicity'? Because both words, 'flight', and 'behaviour', like the visible tips of icebergs, hide a world of complex relations beneath or behind them.

On the one hand the title refers to the attempt, on the part of the main character, Dellarobia Turnbow - a gifted woman who never had the opportunity to go to college - to 'flee' from her suffocating housewife-life on a struggling ('hillbilly') farm in rural Tennessee with her husband, Cub, and two young children, Preston and Cordelia, despite her love for whom she still feels unsatisfied. In the first place the 'behaviour' indicates the way in which this initial attempt at 'flight' happens - a would-be assignation with a sexy telephone technician, in a hut on a forested mountain, which Dellarobia knows, 
with a certain 'rapture' (or recklessness), would probably tear her and her family's life apart, but does not really care as she struggles up the mountain side dressed in the most inappropriate (because chosen for sex-appeal) clothes.

Only...the tryst does not happen, because of an exemplary enactment of Lacan's dictum, 'The letter always arrives at its destination' (Evans 1996: 103), meaning: under certain circumstances an event, functioning as if it were a (mute) 'letter', will appear to be addressed specifically to the person experiencing the event, which demands interpretation because of the 'structural' position of the recipient, in this case Dellarobia. In Dellarobia's case this 'structural position' (or cause) of experiencing the event as a (mute) 'letter' to be interpreted, is unconscious guilt as a married woman, for what she is about to do, and she experiences the event, when it overpowers her, like a 'Moses and the burning bush' kind of happening. The event addresses her as a transfixing 'interpellation' (a peremptory 'legal interruption' of sorts, or perhaps as an instance of the Kantian 'mathematical sublime', which defies imagination; Kant 1969: 99-107 ), and assumes the guise of what seems like a forest being aflame in its entirety, and yet not burning, ostensibly emitting undulating orange waves. This has the effect on Dellarobia of inducing in her the firm belief that it is a kind of quasi-divine 'message' or command, addressed specifically to her, to turn around, ditch the sexual assignation with the hunk, and go home, which is what she does. The 'structural position' on which Dellarobia's interpretation of the event as a divinely sanctioned forest 'aflame' is predicated, and which is an index of the complex relations in which her life is inscribed, is evident where Kingsolver (2012: 19-21) writes that:

No words came to her that seemed sane. Trees turned to fire, a burning bush. Moses came to mind, and Ezekiel, words from Scripture that occupied a certain space in her brain but no longer carried honest weight, if they ever had. Burning coals of fire went up and down among the living creatures...

She was on her own here, staring at glowing trees. Fascination curled itself around her fright. This was no forest fire. She was pressed by the quiet elation of escape and knowing better and seeing straight through to the back of herself, in solitude. This was not just another fake thing in her life's cheap train of events, leading up to this day of sneaking around in someone's thrown-away boots. Here that ended. Unearthly beauty had appeared to her, a vision of glory to stop her in 
the road. For her alone these orange boughs lifted, these long shadows became a brightness rising. It looked like the inside of joy, if a person could see that. A valley of lights, an ethereal wind. It had to mean something.

What it turns out to mean, in the end, after an initial perception of the phenomenon as being some divine revelation - as its 'presence' on the Turnbow farm gradually filters through the religious (and superstitious) little community of the surrounding area - is that it is a colossal migrating column of about fifteen million Monarch butterflies, displaced from their usual area for overwintering in Mexico, to the cold Appalachian mountains of Tennessee. This is the second meaning of the eponymous 'flight behaviour'. (It is possible that Kingsolver wrote this novel on the topic of migrating butterflies to hint at complexity, because of what is called the 'butterfly effect', referred to earlier.) What Kingsolver therefore deftly weaves into the narrative, so subtly that some readers may not comprehend that it constitutes the indispensable 'spine' of the plot, as it were, is the phenomenon euphemistically referred to as 'climate change', but whose more accurate name is 'global warming'. The latter is virtually a swear word in certain quarters, including that of Donald Trump, the current presidential embarrassment of America. And one of the strongest 'messages' of the novel - one most pertinent for curriculum studies - is that human beings are doing their children a grave disservice by not making an awareness of, and thorough information on, the causes and likely effects of global warming the mainstay of the curriculum. This applies first of all to the science (particularly biology) curriculum, of course, but ultimately across the board to all disciplines. This novel by Barbara Kingsolver should be taught in every school in the world, given its lucidity, its passion, and its canny focus on the oft-denied effects of 'climate change'.

Returning to Flight Behaviour, the point about the butterflies bears repeating, given its symptomatic significance: they should not be there, so far away from the places where they are usually found - somewhere between relatively warm Mexico, where they hibernate in winter, and cold Canada, a distance of about 4000 kilometres, that they fly annually (see 'Millions of Monarch Butterflies' under References). Their arrival in the cold Appalachians, instead of the warm forests of Mexico, could mean their extinction, a possibility that gives Dr Ovid Byron - the leading lepidopterist (an entomologist specialising in butterflies) authority on Monarchs in the 
world, who travels to Tennessee to study the incongruous appearance of Monarch butterflies on the Turnbow farm - and Dellarobia (who gets to know, understand, and identify with him) sleepless nights. To highlight its human import, Kingsolver has set this tale of two kinds of 'flight behaviour' in the context of the most consistently ignored - despite being increasingly evident phenomenon of our time, namely climate change. She dramatically weaves the fate of the butterflies together with that of Dellarobia, her children, husband, parents-in-law and extended community of Feathertown, and by implication, the rest of all living beings in the world, which comprises precisely the kind of overarching complex system discussed earlier. In the process of reading this riveting novel one discovers the contrast between denialism, represented by the largely ignorant community of Feathertown (but also further afield), and informed, albeit revisable (because of the complexities involved) scientific knowledge, represented by Dr Byron and his entomological colleagues. The latter eventually include Dellarobia, whose life changes fundamentally because of her incremental involvement with the Monarchs and their fate. If parents or teachers want to employ outstanding literature to teach students about the implications and consequences of climate change (a 'complex' phenomenon), this is the kind of literature they should teach. It would contribute to erasing ignorance (like that of Donald Trump and his ilk) in favour of openness to knowledge, which will, in turn, help one prepare for an increasingly uncertain future.

To demonstrate what I mean by this, consider that, at one point in the narrative, Dr Byron 'loses his cool' altogether because of the tendency of the media to distort accurate scientific information about the effects of climate change in order to assuage its possible alarming impact upon viewers, and affect their own ratings negatively to boot. This occurs when he is interviewed for a television programme by a person who wants to share only the 'beauty of the butterflies' on the Turnbow farm with viewers (in her quest for good viewer-ratings), instead of bringing them insight into what the butterflies' anomalous presence in the Appalachians are symptomatic of. When she finally concedes that 'something new is happening here', following this admission with the obvious question, 'do you think it might possibly be a sign of some deeper problem with the ecology?' he can restrain himself no longer, and shouts at her (Kingsolver 2012: 504):

Yes!.... A problem with the environment, is what you're trying to say. 
Pervasive environmental damage. This is a biological system falling apart along its seams. Yes...

Unseasonable temperature shifts, droughts, a loss of synchronization between foragers and their host plants [A reference to the Monarchs; BO]. Everything hinges on the climate.

Still intent on rescuing the interview for her television programme, the interviewer, Tina Ultner, attempts to insert the usual disingenuous, neoconservative uncertainty or doubt into the interview by remarking that (Kingsolver 2012: 505): 'Scientists of course are in disagreement about whether this is happening, and whether humans have a role'. However, Dr Byron is quick to repudiate her (2012: 505-507):

I'm afraid you've missed the boat, Tina. Even the most recalcitrant climate scientists agree now, the place is heating up. Pretty much every one of the lot...

What scientists disagree on now, Tina, is how to express our shock. The glaciers that keep Asia's watersheds in business are going right away. Maybe one of your interns could Google that for you. The Arctic is genuinely collapsing. Scientists used to call these things the canary in the mine. What they say now is, The canary is dead. We are at the top of the Niagara Falls, Tina, in a canoe. There is an image for your viewers. We got here by drifting, but we cannot turn around for a lazy paddle back when you finally stop pissing around. We have arrived at the point of an audible roar. Does it strike you as a good time to debate the existence of the falls?

Needless to say, the interview is not aired on the television station concerned, but Dellarobia's techno-canny friend, Dovey, who recorded the whole affair audiovisually on her smartphone, promptly posts it online on YouTube for the whole (connected) world to witness what the true position of science on global warming amounts to. This is a bow, on Kingsolver's part, to one of the advantages of the internet (not used sufficiently), namely, to utilise it for critical purposes, instead of exclusively for the dominant, overly narcissistic indulgence of personal 'profile enhancement' by posting selfies on one's Facebook page, for example (sometimes with pathological consequences; see Yahoo Lifestyle Team 2019). 
In sum, what the novel orchestrates in fictional terms - fictional, but rooted in social and natural reality - amounts to the narrative enactment of complex relations: those between Dellarobia, her husband, children and other family members, her best friend (Dovey), and the community members with whom they interact; between Dellarobia and Dr Byron, as well as his graduate students (which is a life-changing interaction for her); between the endangered butterflies and their incongruous new environment, as well as, by implication, their 'natural' environment (in Canada and Mexico) where they have flourished for millennia, but which has been thrown out of kilter by climate change; and between these butterflies and the humans who marvel at them, and study them, and learn from their plight that their own (human) destiny is intricately and intimately intertwined with that of the butterflies via the complex planetary causality that enmeshes them all. Moreover, the lesson Kingsolver teaches one - if you don't already know it - is that through all these interactions, everyone and everything involved is changed.

\section{Conclusion: Literary Fiction and the Curriculum}

As this discussion of Kingsolver's novel shows, literary fiction is an exemplary genre for highlighting something as critically important as climate change or global warming - not only because it demonstrates the dynamics of complex subsystems, but also of their interaction in an even more encompassing ecological arena - in this case the interaction of human social systems with natural ecosystems involving insect migration and bio-degradation (pertaining to the milkweed the Monarchs need for feeding and procreation, as well as the forests where they hibernate, which are often destroyed by logging practices). This may be fiction, but it dramatises the dynamics being enacted on a daily basis in the extant world, and because it exudes passion at various levels of character engagement, it is likely to address students more powerfully than a scientific textbook, regardless of the latter's accuracy and informational value. It should be supplemented by scientific study, and vice versa, of course - that goes without saying. And curricula should allow for such supplementation.

Unless curricula are systematically designed with a view to accommodating an awareness, and recognition, of the fact that human lives are ineluctably inscribed within complex systems which interact in (often untraceable) complex patterns, the teaching of an exemplary novel such as Flight Behaviour would perhaps impart a consciousness of such complexity to 
students, but would not serve its purpose fully. Such an aim would, or should, be to demonstrate that it dovetails with the manner in which other disciplines are (also) taught - an approach that is predicated on the complex interrelations among disciplines, in the first place, which, in turn, mirrors the complex interrelations among all the various subsystems comprising the overarching ecosystem on the planet which is our home, and which is in imminent peril. The reason why it is in peril is the same as the reason for the urgency of introducing complexity systematically into curricula: because there are no borders. Everything is (inter-)connected, and therefore affected when change takes place in any subsystem of the totality of systems.

\section{References}

Cilliers, P. 1998. Complexity and Postmodernism. Understanding Complex Systems. London: Routledge.

Derrida, J. 1978. Structure, Sign and Play in the Discourse of the Human Sciences. In Bass, A. (trans): Writing and Difference. London: Routledge. De Saussure, F. 1959. Course in General Linguistics. Baskin, W. (trans.). New York: Philosophical Library.

Encyclopaedia Brittanica. 2019. Uncertainty Principle - Physics. Updated $3^{\text {rd }}$ January. Available at: https://www.britannica.com/science/uncertaintyprinciple (Accessed on 14 February 2019.)

Evans, D. 1996. An Introductory Dictionary of Lacanian Psychoanalysis. London: Routledge.

Fowles, J. 1997. Mantissa. Boston: Back Bay Paperbacks.

Fowles, J. 1977. The French Lieutenant's Woman. St Albans: Triad Panther. Fowles, J. 1983. The Magus. A Revised Version. London: Triad Panther. Harvey, D. 1989. The Condition of Postmodernity. Oxford: Basil Blackwell. Kant, I. 1969. The Critique of Judgement. Meredith, J.C. (trans.). Oxford: Clarendon Press.

Kierkegaard, S. 1971. Either/ Or. Volume I. Swenson, D.F. \& L.M. Swenson (trans.). Princeton, N.J.: Princeton University Press.

Kierkegaard, S. 1971a. Either/Or. Volume. II. Lowrie, W. (trans.). Princeton, N.J.: Princeton University Press.

Kingsolver, B. 1999. The Poisonwood Bible. New York: Harper Perennial. Kingsolver, B. 2012. Flight Behaviour. London: Faber and Faber. 
Kovel, J. 2007. The Enemy of Nature. The End of Capitalism or the End of the World? London: Zed Books.

Lacan, J. 1977. The Direction of the Treatment and the Principles of its Power. In Sheridan, A. (trans.). Écrits: A Selection. New York: W.W. Norton.

Lacan, J. 1977a. The Agency of the Letter in the Unconscious or Reason Since Freud. In Sheridan, A. (trans). Écrits: A Selection. New York: W.W. Norton.

Melchert, N. 1991. The Great Conversation - A Historical Introduction to Philosophy. London: Mayfield Publishing Company.

Millions of Monarch Butterflies: YouTube: Available at: https://www.youtube.com/watch?v=AN8-pNnvJ5s (Accessed on 14 February 2019.)

Morrison, K. 2008. Educational Philosophy and the Challenge of Complexity Theory. In Mason, M. (ed.): Complexity Theory and the Philosophy of Education. Oxford: Wiley-Blackwell. https://doi.org/10.1111/j.14695812.2007.00394.x

Olivier, B. 1998. The Sublime, Unpresentability and Postmodern Cultural Complexity. In Olivier, B. (ed.): Critique, Architecture, Culture, Art. Port Elizabeth: University of Port Elizabeth.

Olivier, B. 2005. Beyond Kierkegaard's Aesthetic and Ethical Models as Paradigms of Art. South African Journal of Art History 20: 176 - 187.

Olivier, B. 2008. Negotiating the Paranoiac Structure of Human Knowledge: Fowles's The Magus and Lacan. South African Journal of Psychology 38,1: 176 - 199. https://doi.org/10.1177/008124630803800110

Olivier, B. 2017. The Ethical (and Political) Status of Theorising the Subject: Deleuze and Guattari. Psychotherapy and Politics International 15,2: 1 10. Available at:

http://onlinelibrary.wiley.com/wol1/doi/10.1002/ppi.1408/full

(Accessed on 14 February 2019.) https://doi.org/10.1002/ppi.1408

Olivier, B. 2018. Mary Shelley's Frankenstein and Ecological Responsibility. Journal of Literary Studies 34,4: 1 - 25. https://doi.org/10.1080/02564718.2018.1538075

Olivier, B. 2018a. Kingsolver's Narrative Indictment of Colonisation: The Poisonwood Bible. Available at:

https://thoughtleader.co.za/bertolivier/2018/05/15/kingsolvers-narrativeindictment-of-colonisation-the-poisonwood-bible/ (Accessed on 14 February 2019.) 


\section{Bert Olivier}

Peters, M.A. 2008. Foreword: Complexity and Knowledge Systems. In Mason, M. (ed.): Complexity Theory and the Philosophy of Education. Oxford: Wiley-Blackwell,

Shelley, M.W. 1818. Frankenstein. Free Planet EBook.com. Available at:

https://www.planetebook.com/free-ebooks/frankenstein.pdf (Accessed on 7 June 2018.)

Shelton, L.G. 2019. The Bronfenbrenner Primer - A Guide to Develecology.

New York: Routledge. https://doi.org/10.4324/9781315136066

Woolf, V. 1959. The Waves. New York: Harcourt Inc.

Woolf, V. 1994. To the Lighthouse. Hertfordshire: Wordsworth Editions.

Yahoo Lifestyle Team 2019. Teen Left Bedridden by Snapchat Addiction.

Yahoo Style UK, 22 February. Available at:

https://uk.style.yahoo.com/teen-left-bedridden-snapchat-addiction-2093621197.html (Accessed on 14 February 2019.)

Bert Olivier

Department of Philosophy

University of the Free State

OlivierG1@ufs.ac.za 